\title{
A CLINICOPATHOLOGICAL STUDY OF TUMOURS AND TUMOUR-LIKE LESIONS OF THE STOMACH
}

\author{
Rani Kalavathy ${ }^{1}$, Dhamayanthi Suryamoorthy², Revathi Ramakrishnan ${ }^{3}$
}

1 Professor, Department of Pathology, Theni Medical College, Theni.

${ }^{2}$ Associate Professor, Department of Pathology, Theni Medical College, Theni.

${ }^{3}$ Associate Professor, Department of Pathology, Theni Medical College, Theni.

\begin{tabular}{l} 
ABSTRACT \\
\hline BACKGROUND \\
Gastric cancer is the second most cancer worldwide after lung cancer despite a global decline in its incidence. ${ }^{1}$ In most countries, \\
the annual incidence of new cases of gastric cancer ranges between 8 and 20 per 100,000 population. Gastric cancer is primarily a \\
disease of the old and the rates rise with increasing age and reaches a peak in the sixth and seventh decades.
\end{tabular}

\section{MATERIALS AND METHODS}

This study includes 155 cases of tumours and tumour-like lesions of the stomach. All the biopsy materials along with full clinical details and operative findings as per the working formulation were received. The biopsy materials received were fixed in $10 \%$ buffered formalin. Punch biopsy, wedge biopsy and polypectomy specimens were subjected to histopathological examination in toto. Samples for histopathological study were taken from the tumour, the surrounding mucosa, proximal and distal lines of resection, lymph node and other organs resected in the case of radical gastrectomies.

\section{OBSERVATIONS AND RESULTS}

In the three years study period from September 1988 to August 2001,33,329 biopsy materials were received. Of these, tumours and tumour-like lesions of the stomach accounted for 155 cases. Hence, the overall incidence of tumours and tumour-like lesions of the stomach is $0.47 \%$. No benign tumour was reported during the period. The malignant tumours were the most common with a peak incidence in the $4^{\text {th }}$ and $5^{\text {th }}$ decade and increased preponderance of malignant neoplasms in males when compared to females. The current study showed a high incidence of malignancy in the antrum. The most common histological type is the tubular adenocarcinoma forming $78.29 \%$. The incidence of mucinous adenocarcinoma was $8.55 \%$.

\section{CONCLUSION}

The study is to analyse the incidence, to classify the benign and malignant tumours and tumour-like lesion of the stomach and study their prevalence along with the clinical correlation and to study the age and sex incidence of tumours and tumour-like lesions of the stomach.

\section{KEYWORDS}

Stomach, Tumour, Clinicopathology.

HOW TO CITE THIS ARTICLE: Kalavathy R, Suryamoorthy D, Ramakrishnan R. A clinicopathological study of tumours and tumourlike lesions of the stomach. J. Evolution Med. Dent. Sci. 2016;5(64):4569-4577, DOI: 10.14260/jemds/2016/1042

\begin{abstract}
INTRODUCTION
Gastric cancer is the second most cancer worldwide after lung cancer, despite a global decline in its incidence. ${ }^{1}$ In most countries, the annual incidence of new cases of gastric cancer ranges between 8 and 20 per 100,000 population. Highest rates in the world are seen in Japan and China and it is a major clinical problem in India. It is a leading cancer amongst the male population of Chennai. ${ }^{2}$ Gastric cancer is primarily a disease of the old and the rates rise with increasing age and reaches a peak in the sixth and seventh decades. The overall 5 years survival rate is low, because majority of gastric cancers are diagnosed in advance ( $<5 \%$ for stage IV). Gastric cancer when confined to mucosa and submucosa (i.e. early gastric

is primarily dependent on the stage of the cancer. In high prevalence areas such as Japan and China, mass screening methods by radiological and endoscopic tests have been for detection of early gastric cancer.

The study is to analyse the incidence, to classify the benign and malignant tumours and tumour-like lesion of the stomach and study their prevalence along with the clinical correlation, to study the age and sex incidence of tumours and tumour-like lesions of the stomach. This study is to also analyse the site wise distribution of the various neoplasms of the stomach and we do the histological typing of the tumours and tumour-like lesions based on W.H.O. classification and study any associated changes in the non-neoplastic mucosa.
\end{abstract} carcinoma) shows a 5 years survival rate varying from $65 \%$ to $98 \%$. The end result of treatment for gastric cancer

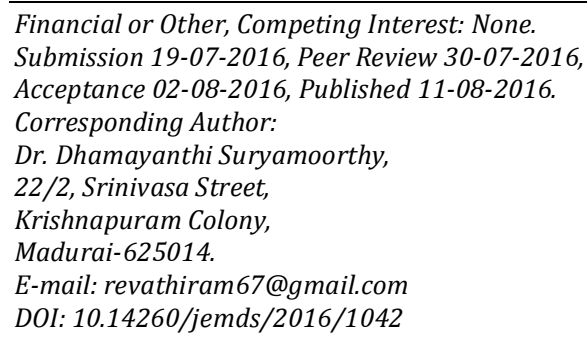

\section{MATERIALS AND METHODS}

2,42,346 patients were taken from September 1988 to August 2001. During this study period, there were 155 cases of tumours and tumour-like lesions of the stomach.

The present study evaluates various parameters of these gastric neoplasms including their incidence and distribution according to age, sex and site.

The following types of gastric biopsy materials were received.

1. Punch biopsy.

2. Wedge biopsy. 
3. Polypectomy.

4. Gastrectomy specimens.

All the biopsy materials along with full clinical details and operative findings as per the working formulation were received. The biopsy materials received were fixed in $10 \%$ buffered formalin. Punch biopsy, wedge biopsy and polypectomy specimens were subjected to histopathological examination in toto. With the gastrectomy specimens, parameters noted include length of the specimen, size, shape and consistency of tumour, distance of tumour from the resected margins; status of the resected margins (Positive or negative); presence of lymph nodes, etc.

Samples for histopathological study were taken from the tumour, the surrounding mucosa, proximal and distal lines of resection, lymph node and other organs resected in the case of radical gastrectomies (eg. spleen, transverse colon, etc.).

The tissues were processed by paraffin-processing. Paraffin blocks were prepared subsequently and 5 micron thin sections were cut from the paraffin blocks and stained with haematoxylin and eosin. ${ }^{3}$ Wherever it was essential, the following special stains were used.

\section{Special Stains Uses}

1. PAS neutral mucin.

2. Alcian blue for acidic mucin.

3. Alcian blue-PAS for acidic and neutral mucins.

4. Reticulin to differentiate between lymphoma and poorly differentiated carcinoma.

Standard methods of staining as described by Bancoft in theory and practice of histological techniques were followed. Based on histopathology, the lesions were placed into one of the following categories, viz. benign and malignant neoplasms, tumour-like lesions and inflammatory lesions. The study mainly involves the benign and malignant tumours and tumour-like lesions of the stomach.

Photographs of the appropriate specimens and photomicrographs of the sections were taken. The classification of the gastric neoplasms used in the study is based on the W.H.O. histological typing of gastric and oesophageal tumours no. 18, 1977 edited by Oota K. and Sobin L.H. ${ }^{4}$

\section{OBSERVATION AND RESULTS}

Incidence of tumours and tumour-like of the stomach. In the three years study period from September 1988 to August 2001, 33,329 biopsy materials were received. Of these, tumours and tumour-like lesions of the stomach accounted for 155 cases. Hence, the overall incidence of tumours and tumour-like lesions of the stomach is $0.47 \%$.

Diagram 1 shows the year-wise distribution of the tumours and tumour-like lesions of the stomach during the study period.

Diagram 2 depicts the overall incidence of tumours and tumour-like lesions of the stomach that were received during the study period. No benign tumour was reported during the period.

\section{Age Incidence}

The age distribution of tumours and tumour-like lesions of the stomach is depicted in Diagram 3. The malignant tumours were the most common with a peak incidence in the $4^{\text {th }}$ and $5^{\text {th }}$ decade.

\section{Sex Incidence}

Of the total 155 tumours and tumour-like lesions of the stomach, 100 cases occurred in males (64.52\%) and 55 in females (35.48\%) as shown in Table 1 . The current study showed an increased preponderance of malignant neoplasms in males when compared to females, malignant tumours of the stomach.

\section{Incidence}

Of the 33,229 biopsy materials analysed in the three-year study, there were 152 cases of malignant tumours with an overall incidence of $0.46 \%$.

\section{Age Incidence}

A wide age range extending from 10 to 70 years with an average age of 45 years has been noted in the current study. Table 2 illustrates the decennial age incidence of gastric malignancies. Most of the cases are found in the age group 4160 years (65.13\%). As much as $22.37 \%$ cases were found to be younger than 40 years, there were no patients older than 70 years and the youngest patient was 19 years old in the current study.

\section{Sex Incidence}

Table 1 shows the sex incidence of malignant tumours of the stomach. It was noted that $64.47 \%$ of malignancies occurred in men compared to $35.53 \%$ in females. Thus, there is a near 2:1 ratio for male-to-female incidence of gastric cancer.

\section{Distribution of Malignant Tumours According to the Anatomical Site}

The current study showed a high incidence of malignancy in the antrum (29.58\%) as shown in Table 3. Tumours occurring in the body and antrum together showed an incidence of $26.06 \%$. The tumours of cardia showed a low incidence of $7.04 \%$. There were 3 cases of tumours arising from the gastric remnant $(2.11 \%)$.

\section{Signs and Symptoms}

Table 4 shows the most common signs and symptoms of gastric cancer patients in the present study. Most patients present with abdominal pain and vomiting, vomiting was the predominant symptom in advanced malignancies. Few patients had haematemesis and some presented with abdominal mass. The constitutional symptoms like loss of weight and loss of appetite alone were the presenting complaints in a very few percentage of cases. The patients with involvement of cardia (proximal third) presented with dysphagia.

\section{Clinical Staging of Gastric Adenocarcinoma}

Out of 142 cases of adenocarcinomas, only 61 were gastrectomy specimens. Staging was done based on TNM classification as shown in Table 5,5 on all gastrectomy specimens received in our institution. Excluding the undefined category, the commonest stage encountered was stage II $(16.90 \%)$ and the next commonest was stage IIIA (12.68\%) Table 6. 
Histologic Distribution of Malignant Tumours of the Stomach

Incidence of the various histologic types of the malignant tumours of the stomach in the current study is depicted in Table 7. The most common histological type is the tubular adenocarcinoma forming $78.29 \%$. The incidence of mucinous adenocarcinoma was $8.55 \%$. Only three cases of papillary adenocarcinoma were encountered and 7 cases of signet ring cell carcinoma. The incidence of neuroendocrine tumours was $3.29 \%$. The incidence of lymphomas was as low as 3.29\%.

Metastatic deposits of the 142 cases of adenocarcinoma in the study; clinical regional lymph node involvement was seen in 65 cases, of which 31 cases were positive histologically for secondaries. Two patients had ovarian secondaries. Clinically omental and peritoneal deposits were seen in 7 cases; supraclavicular lymph node involvement in one patient, 5 patients had liver secondaries; 1 had secondary deposits in both lungs and one each showed infiltration of pancreas of pancreas and spleen. However, biopsy confirmation was not made in these cases.

\section{Tumour-Like Lesions of the Stomach}

Table 8 shows the incidence of tumour-like lesions of the stomach. Hyperplastic polyps were the commonest in the present study $(66.67 \%$ incidence). One case of a hamartomatous polyp was reported.

\begin{tabular}{|c|c|c|c|c|}
\hline \multirow{2}{*}{$\begin{array}{c}\text { Tumour } \\
\text { Type }\end{array}$} & $\begin{array}{c}\text { Males } \\
\text { Total } \\
\text { No. of } \\
\text { Cases }\end{array}$ & Incidence & $\begin{array}{c}\text { Total } \\
\text { No. of } \\
\text { Cases }\end{array}$ & Incidence \\
\hline Malignant & 98 & $64.47 \%$ & 54 & $35.53 \%$ \\
\hline $\begin{array}{c}\text { Tumour- } \\
\text { like }\end{array}$ & 2 & $66.67 \%$ & 1 & $33.33 \%$ \\
\hline \multicolumn{3}{|c|}{$\begin{array}{c}\text { Table 1: Sex Incidence of Tumours and } \\
\text { Tumour-Like Lesions of the Stomach }\end{array}$} \\
\hline
\end{tabular}

\begin{tabular}{|c|c|c|c|c|c|c|}
\hline \multirow{2}{*}{ Decade } & \multicolumn{2}{|c|}{ Current Study } & \multicolumn{2}{|c|}{ Srinivasan } & \multicolumn{2}{|c|}{ Brennan and Karbeh } \\
\hline & No. of Cases & Incidence & No. of Cases & Incidence & No. of Cases & Incidence \\
\hline $0-10$ & $*$ & $*$ & $*$ & $*$ & $*$ & $*$ \\
\hline $11-20$ & 1 & $0.66 \%$ & $*$ & $*$ & $*$ & $*$ \\
\hline $21-30$ & 9 & $5.92 \%$ & $*$ & $*$ & 16 & $1.01 \%$ \\
\hline $31-40$ & 24 & $15.79 \%$ & 5 & $11.36 \%$ & 83 & $5.21 \%$ \\
\hline $41-50$ & 48 & $31.58 \%$ & 24 & $54.55 \%$ & 201 & $12.63 \%$ \\
\hline $51-60$ & 51 & $33.55 \%$ & 11 & $25 \%$ & 31 & $23.93 \%$ \\
\hline $61-70$ & 19 & $12.5 \%$ & 3 & $6.82 \%$ & 467 & $29.33 \%$ \\
\hline $71-80$ & $*$ & $*$ & 1 & $2.27 \%$ & 349 & $21.92 \%$ \\
\hline $81-90$ & $*$ & $*$ & $*$ & $*$ & 92 & $5.78 \%$ \\
\hline$>90$ & $*$ & $*$ & $*$ & $*$ & 3 & $0.19 \%$ \\
\hline \multicolumn{7}{|c|}{ *Not Encountered } \\
\hline
\end{tabular}

\begin{tabular}{|c|c|c|c|c|}
\hline \multirow{2}{*}{ Location } & \multicolumn{2}{|c|}{ Current Study } & \multicolumn{2}{c|}{ Borch K et al } \\
\cline { 2 - 5 } & $\begin{array}{c}\text { No. of } \\
\text { Cases }\end{array}$ & $\begin{array}{c}\text { Incidence } \\
\text { (\%) }\end{array}$ & $\begin{array}{c}\text { No. of } \\
\text { Cases }\end{array}$ & $\begin{array}{c}\text { Incidence } \\
\text { (\%) }\end{array}$ \\
\hline Cardia & 10 & 7.04 & 129 & 11 \\
\hline Body & 18 & 12.68 & 302 & 26 \\
\hline Antrum & 42 & 29.58 & 273 & 24 \\
\hline $\begin{array}{c}\text { Body and } \\
\text { antrum }\end{array}$ & 37 & 26.06 & 195 & 17 \\
\hline $\begin{array}{c}\text { Gastric } \\
\text { remnant }\end{array}$ & 3 & 2.11 & 105 & 9 \\
\hline Undefined & 32 & 22.54 & 157 & 14 \\
\hline Total & 142 & 100 & 1161 & 100 \\
\hline Table 3: Tumour Location in Patients with Gastric \\
Adenocarcinoma - A Comparative Study \\
\hline \multicolumn{5}{|c}{} \\
\hline
\end{tabular}

\begin{tabular}{|c|c|c|}
\hline Signs/Symptoms & Total Cases & Incidence (\%) \\
\hline Loss of weight & 6 & 3.95 \\
\hline Loss of appetite & 9 & 5.92 \\
\hline Pain abdomen & 46 & 30.26 \\
\hline Vomiting & 52 & 34.21 \\
\hline Haematemesis & 11 & 7.24 \\
\hline Mass abdomen & 14 & 9.21 \\
\hline Ascites & 5 & 3.29 \\
\hline Dysphagia & 3 & 1.97 \\
\hline Melena & 6 & 3.95 \\
\hline \multicolumn{3}{|c|}{$\begin{array}{c}\text { Table 4: Incidence of Signs and Symptoms in Gastric } \\
\text { Malignancy in the Current Study }\end{array}$} \\
\hline
\end{tabular}

TABLE 5: TNM CLASSIFICATION FOR ADENOCARCINOMA OF STOMACH ${ }^{5}$

\section{Primary Tumour}

Tx Primary tumour cannot be assessed.

To No evidence of primary tumour.

$\mathrm{T}_{\text {is }}$ Carcinoma in situ.

$\mathrm{T}_{1}$ Tumour invades lamina propria or submucosa.

$\mathrm{T}_{2}$ Tumour invades muscularis propria.

$\mathrm{T}_{3}$ Tumour invades adventitia.

$\mathrm{T}_{4}$ Tumour invades adjacent structures.

\section{Regional Lymph Nodes}

$\mathrm{N}_{\mathrm{X}}$ Regional lymph node(S) cannot be assessed.

No No regional lymph node metastasis.

$\mathrm{N}_{1}$ Metastasis in perigastric lymph node(s) within $3 \mathrm{~cm}$ of edge of primary tumour.

$\mathrm{N}_{2}$ Metastasis in perigastric lymph node(s) more than 3c from edge of primary tumour or in lymph node along left gastric, common hepatic, splenic or celiac arteries.

\section{Distant Metastasis}

Mx Presence of distant metastasis cannot be assessed

Mo No distant metastasis.

M1 Distant metastasis. 
Stage Grouping

Stage 0 Tis, N0, M0

Stage IA T1, N0, M0

Stage IB T1, N1, M0, T2, N0, M0

Stage II T1, N2, M0

Stage IIIA T2, N2, M0

Stage IIIB T3, N2, M0 T2, N1, M0 T3, N1, M0 T4, N1, M0

Stage IV T4, N2, M0, Any T, Any N, M

\begin{tabular}{|c|c|c|c|c|c|}
\hline \multirow{2}{*}{$\begin{array}{c}\text { TNM } \\
\text { Stage }\end{array}$} & \multicolumn{2}{|c|}{$\begin{array}{c}\text { Current } \\
\text { Study }\end{array}$} & \multicolumn{2}{c|}{$\begin{array}{c}\text { Borch } \\
\text { K. et al } \\
1974-1991\end{array}$} & $\begin{array}{c}\text { Jin-Pok } \\
\text { Kim } \\
1981- \\
1996\end{array}$ \\
\cline { 2 - 6 } & $\begin{array}{c}\text { No. } \\
\text { of } \\
\text { Cases }\end{array}$ & $\begin{array}{c}\text { Incidence } \\
\text { (\%) }\end{array}$ & $\begin{array}{c}\text { No. } \\
\text { of } \\
\text { Cases }\end{array}$ & $\begin{array}{c}\text { Incidence } \\
\text { (\%) }\end{array}$ & $\begin{array}{c}\text { Incidence } \\
\text { (\%) }\end{array}$ \\
\hline IA & 4 & 2.81 & 45 & 4 & 19.2 \\
\hline IB & 3 & 2.11 & 140 & 12 & 11.9 \\
\hline II & 24 & 16.90 & 98 & 8 & 13.6 \\
\hline IIIA & 18 & 12.68 & 118 & 10 & 17.7 \\
\hline IIIB & 7 & 4.93 & 118 & 10 & 22.3 \\
\hline IV & 5 & 3.52 & 329 & 28 & 15.2 \\
\hline Undefined & 81 & 57.04 & 313 & 27 & - \\
\hline Table 6: Incidence of Cases of Adenocarcinoma of the \\
Stomach in Each Stage: A Comparative Study \\
\hline
\end{tabular}

\begin{tabular}{|c|c|c|c|c|}
\hline \multirow[b]{2}{*}{ Histologic Type } & \multicolumn{2}{|c|}{ Current Study } & \multicolumn{2}{|c|}{ Srinivasan } \\
\hline & $\begin{array}{l}\text { No. of } \\
\text { Cases }\end{array}$ & $\begin{array}{c}\text { Incidence } \\
(\%)\end{array}$ & $\begin{array}{l}\text { No. of } \\
\text { Cases }\end{array}$ & $\begin{array}{c}\text { Incidence } \\
(\%)\end{array}$ \\
\hline $\begin{array}{c}\text { Tubular } \\
\text { adenocarcinoma }\end{array}$ & 119 & 78.29 & 29 & 66 \\
\hline $\begin{array}{c}\text { Papillary } \\
\text { adenocarcinoma }\end{array}$ & 3 & 1.97 & * & $*$ \\
\hline $\begin{array}{c}\text { Mucinous } \\
\text { adenocarcinoma }\end{array}$ & 13 & 8.55 & 13 & 29.55 \\
\hline $\begin{array}{c}\text { Signet ring cell } \\
\text { carcinoma }\end{array}$ & 7 & 4.61 & * & * \\
\hline $\begin{array}{c}\text { Neuroendocrine } \\
\text { Tumours }\end{array}$ & 5 & 3.29 & * & * \\
\hline Lymphomas & 5 & 3.29 & 2 & 4.55 \\
\hline $\begin{array}{r}\text { Table 7: Incid } \\
\text { Tumours } 0\end{array}$ & $f t$ & $\begin{array}{l}\text { tolog } \\
-A C\end{array}$ & 2 & $\begin{array}{l}\text { Ialignant } \\
\text { Study }\end{array}$ \\
\hline
\end{tabular}

\begin{tabular}{|c|c|c|c|c|}
\hline \multirow{2}{*}{$\begin{array}{c}\text { Tumour-Like } \\
\text { Lesions }\end{array}$} & \multicolumn{2}{|c|}{ Current Study } & \multicolumn{2}{c|}{ Seifert and Elster } \\
\cline { 2 - 5 } & $\begin{array}{c}\text { No. of } \\
\text { Cases }\end{array}$ & Incidence & $\begin{array}{c}\text { No. of } \\
\text { Cases }\end{array}$ & Incidence \\
\hline $\begin{array}{c}\text { Hyperplastic } \\
\text { polyps }\end{array}$ & 2 & $66.67 \%$ & 132 & $57.64 \%$ \\
\hline $\begin{array}{c}\text { Hamartomatous } \\
\text { polyp }\end{array}$ & 1 & $33.33 \%$ & Nil & Nil \\
\hline Total & $\mathbf{3}$ & & $\mathbf{2 2 9}$ & \\
\hline
\end{tabular}

Table 8: The Incidence of Tumour-Like Lesions of Stomach

\begin{tabular}{|c|c|c|c|c|c|c|}
\hline & \multirow{2}{*}{$\begin{array}{c}\text { Total No. of Biopsies (Excluding } \\
\text { Gynaecological (Specimens) }\end{array}$} & \multicolumn{3}{|c|}{ No. of Cases } & \multirow{2}{*}{ Total } & \multirow{2}{*}{ Percentage } \\
\cline { 3 - 6 } & 1,6105 & Nil & 152 & 3 & 155 & 0.96 \\
\hline Current Study & 8571 & Nil & 44 & Nil & 44 & 0.51 \\
\hline $\begin{array}{c}\text { Srinivasan } \\
\text { Study }\end{array}$ & Malignant & $\begin{array}{c}\text { Tumour } \\
\text { Like }\end{array}$ & & & &
\end{tabular}

Table 9: Incidence of Tumours and Tumour-Like Lesions of Stomach - A Comparative Study

\begin{tabular}{|c|c|c|}
\hline Location & Patients & Incidence (\%) \\
\hline Proximal third & 494 & 23.54 \\
\hline Middle third & 393 & 18.72 \\
\hline Distal third & 919 & 73.78 \\
\hline Whole stomach & 148 & 7.05 \\
\hline Unknown & 145 & $\mathbf{1 0 0}$ \\
\hline Total & $\mathbf{2 0 9 9}$ & \\
\hline \multicolumn{2}{|l}{} \\
\hline
\end{tabular}

\begin{tabular}{|c|c|c|c|}
\hline Early Gastric Cancer & Incidence (\%) & Advanced Gastric Cancer & Incidence (\%) \\
\hline Asymptomatic/silent & 80 & Weight loss & 60 \\
\hline Peptic ulcer symptoms & 10 & Abdominal pain & 50 \\
\hline Nausea or vomiting & 8 & Nausea or vomiting & 30 \\
\hline Anorexia & 8 & Anorexia & 30 \\
\hline Early satiety & 5 & Dysphagia & 25 \\
\hline Abdominal pain & 2 & Blood loss & 20 \\
\hline Gastrointestinal blood loss & $<2$ & Early satiety & 20 \\
\hline Weight loss & $<2$ & Peptic ulcer symptoms & 20 \\
\hline Dysphagia & $<1$ & Abdominal mass or fullness & 5 \\
\hline \multicolumn{4}{c}{ Table 11: Incidence of Signs \& Symptoms in Gastric Malignancy } \\
\hline
\end{tabular}

\begin{tabular}{|c|c|c|}
\hline Histologic Type & $\begin{array}{l}\text { No. of } \\
\text { Cases }\end{array}$ & Incidence (\%) \\
\hline Adenocarcinoma & 1282 & 96.32 \\
\hline Lymphoma & 21 & 1.58 \\
\hline Leiomyosarcoma & 18 & 1.35 \\
\hline Carcinoids & 7 & 0.53 \\
\hline Squamous cell carcinoma & 2 & 0.15 \\
\hline Histiocytoma & 1 & 0.8 \\
\hline Total & 1331 & \\
\hline
\end{tabular}

\begin{tabular}{|c|c|c|}
\hline Decade & No. of Cases & Incidence \\
\hline $0-10$ & Nil & 0 \\
\hline $11-20$ & 1 & $0.70 \%$ \\
\hline $21-30$ & 8 & $5.63 \%$ \\
\hline $31-40$ & 22 & $15.49 \%$ \\
\hline $41-50$ & 43 & $30.28 \%$ \\
\hline $51-60$ & 49 & $34.51 \%$ \\
\hline $61-70$ & 19 & $13.38 \%$ \\
\hline
\end{tabular}

Table 14: Age Incidence of Adenocarcinoma of Stomach 


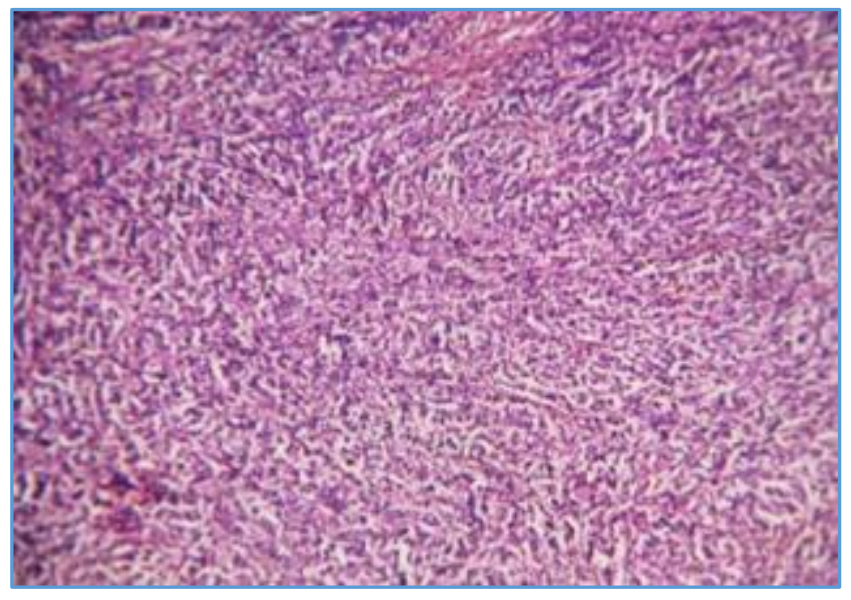

Fig. 1: A Case of Poorly Differentiated Tubular Adenocarcinoma showing Tumour Cells with Attempted Tubular Cells in Some Area H\&E X100

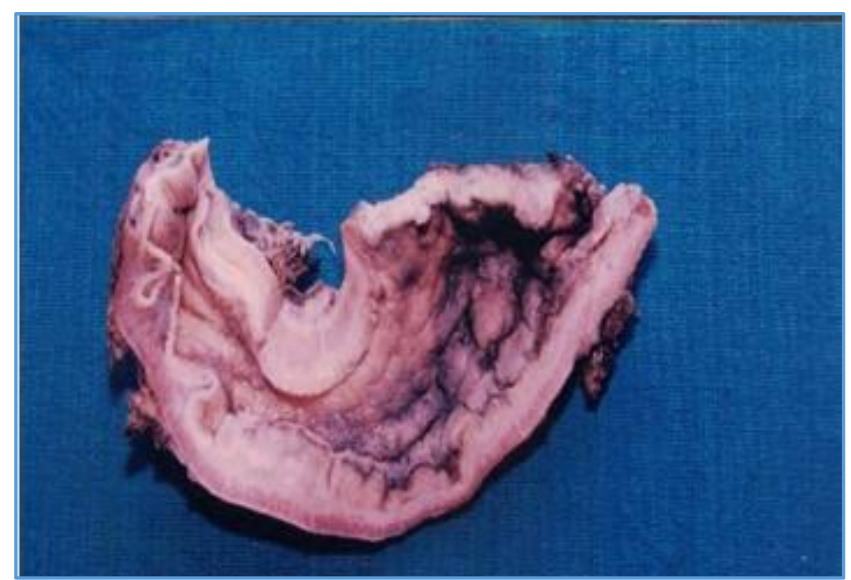

Fig. 2: Gross Appearance of Stomach from a Patient showing Classical Appearance of Linitis Plastica (Leather Bottle Stomach)

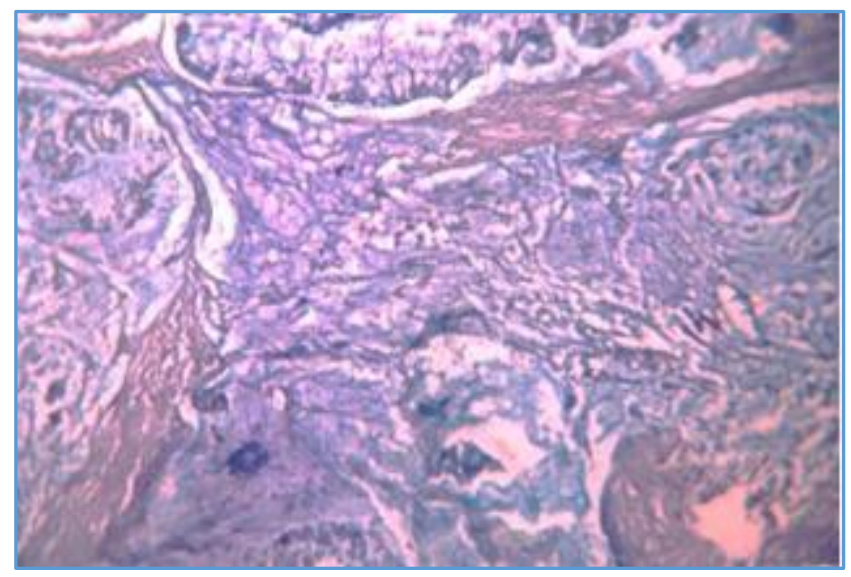

Fig. 3: A Case of Mucinous Adenocarcinoma showing Acid Mucin-Stained with Alcian Blue X100

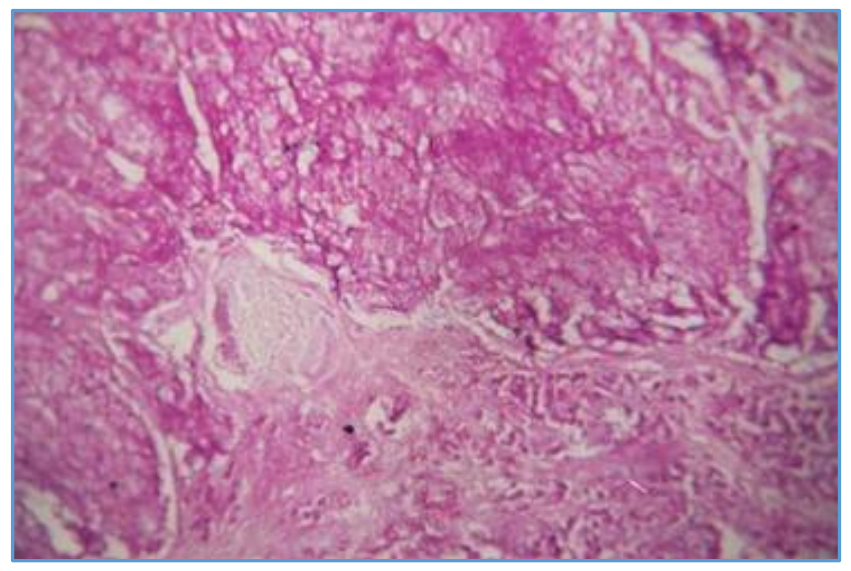

Fig. 4: Adenocarcinoma with Intracytoplasmic and Extracellular Secretary Material showing Positivity for PAS X100

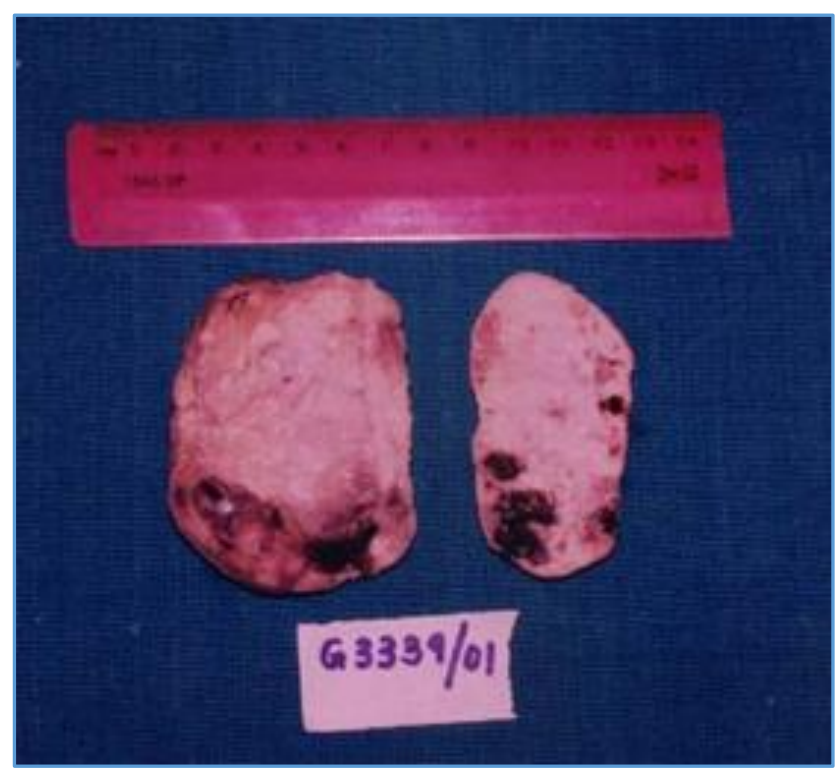

Fig. 5: Gross Appearance of a Specimen from a Case of Krukenberg Tumour showing Greyish-White Appearance with Haemorrhagic Areas

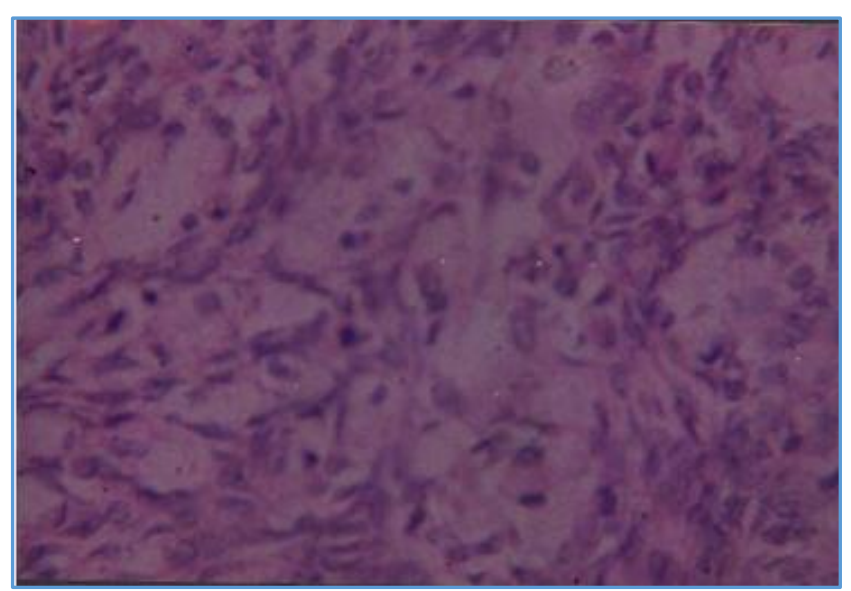

Fig. 6: Photomicrograph of the Section from a Case of Krukenberg Tumour showing Signet Ring Cells H\&E X450 


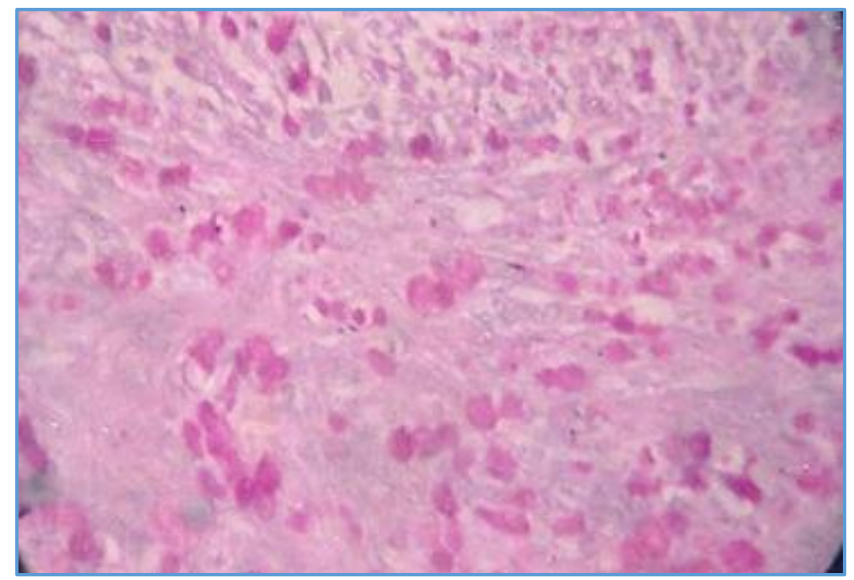

Fig. 7: The Same Case (Mentioned in Fig. 12) showing Signet Ring Cells with PAS Positivity X450

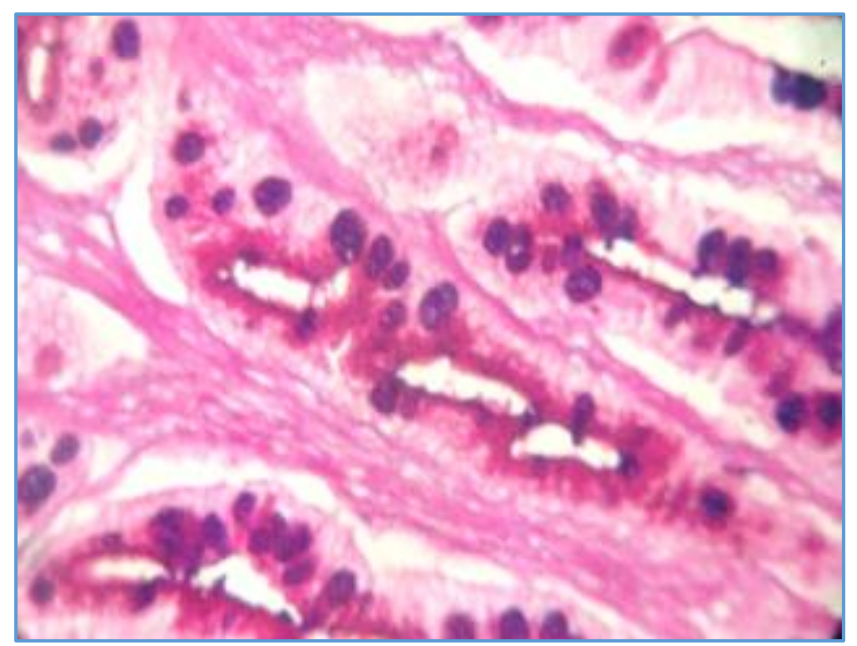

Fig. 8: Complete Intestinal Metaplasia showing Goblet Cells containing Acidic and Neutral Mucin Staining Purple with Alcian Blue X450

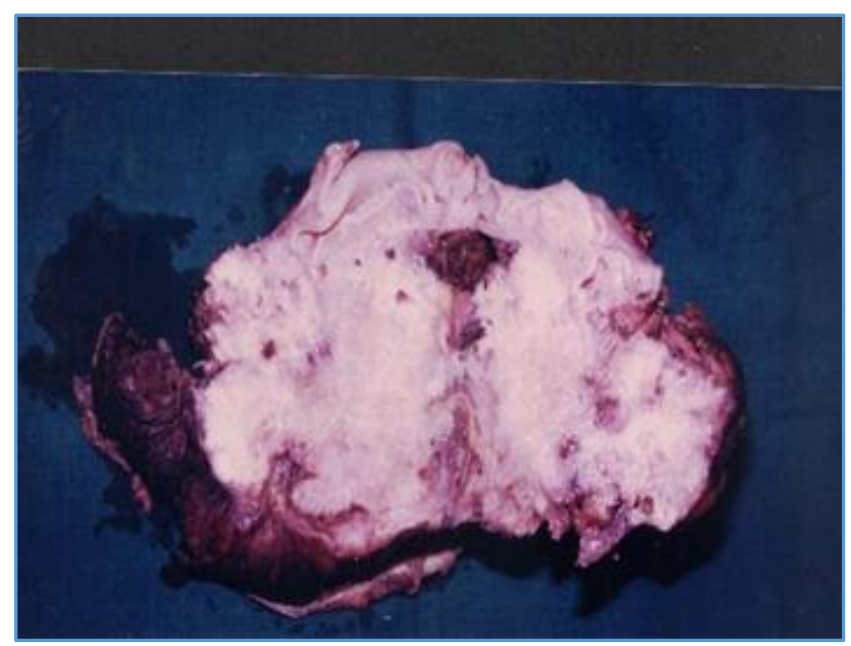

Fig. 9: Gross Appearance of Specimen from a Case of Mucinous Adenocarcinoma showing Perigastric Invasion

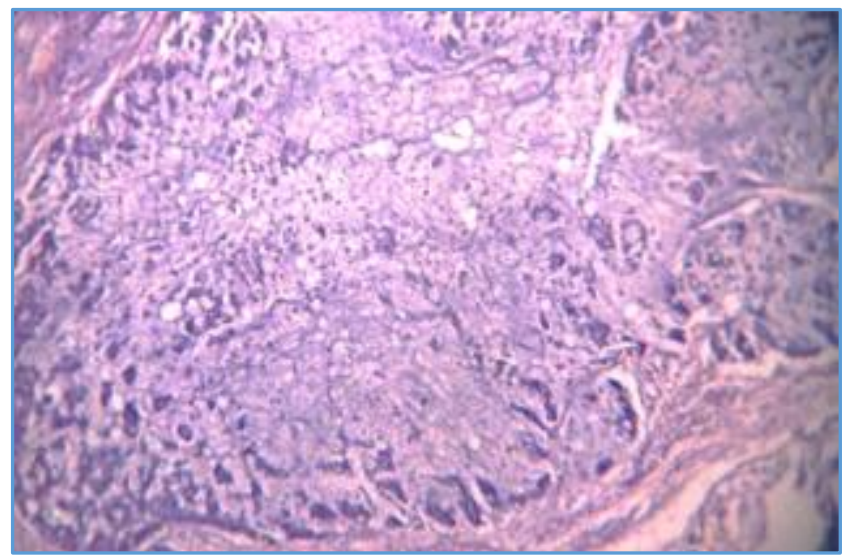

Fig. 10: Photomicrograph shows Colloid Carcinoma with a Tumour Cells Floating in Extracellular Mucin

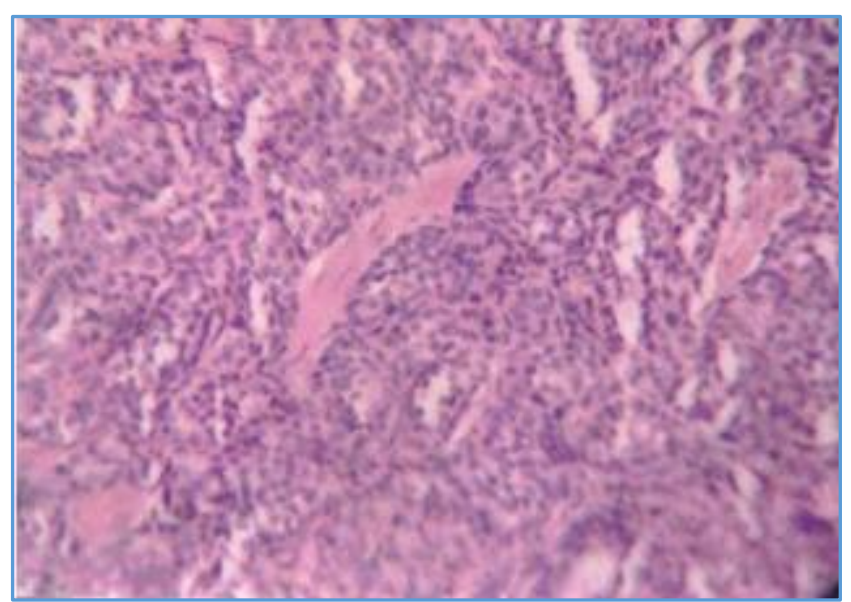

Fig. 11: Photomicrograph showing Carcinoid Tumour with Uniform Tumour Cells arranged in Trabecular Pattern H\&E X450

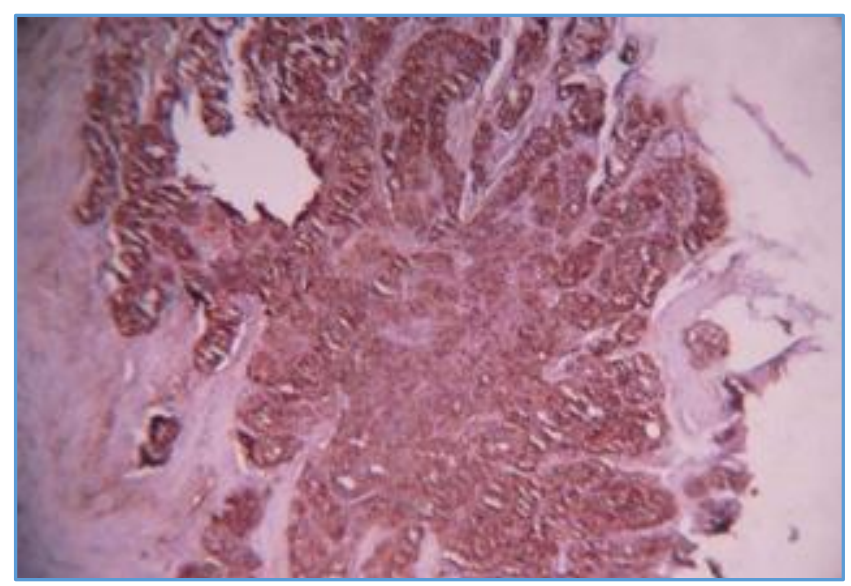

Fig. 12: Photomicrograph of a Case of Carcinoid Tumour showing Positivity for Chromogen $\mathrm{X} 100$

\section{DISCUSSION}

Cancer of the stomach is one of the most common human solid tumours in Asia, despite a worldwide decline in its incidence over the last 4-5 decades. 
In India, Kashmir, Chennai and Bangalore have a very high incidence of gastric cancer. Most gastric cancers are diagnosed in an advanced stage. Even in developed countries like United Kingdom, less than $1 \%$ of all gastric cancers are diagnosed in an early stage. 6

Diagram 8 depicts the overall incidence of tumours and tumours and tumour-like lesions of the stomach during the study period from September 1988 to August 2001.

Total biopsies received during the study period excluding gynaecological specimens are 16,105. Table 9 shows the comparative study on the incidence of tumours and tumourlike lesion of the stomach. In the current study the incidence of $0.96 \%$, which is slightly more than the incidence reported by Srinivasan. ${ }^{7}$ No benign tumour was reported in both the studies. While three tumour-like lesions were reported in the current study, similar lesions were not reported in the study by Srinivasan. The incidence of malignant tumours in the current study was $0.94 \%$, while in his study it was $0.51 \%$ malignant tumours of the stomach.

\section{Age Incidence}

Table 2 illustrates the decennial age incidence of gastric malignancies compared to the study by Srinivasan and the study by Brennan and Karpeh ${ }^{8}$ at Memorial Sloan Kettering Cancer Centre (MSKCC), New York, from July 1, 1985 to July 1, 1995. Overall findings were almost similar regarding the age incidence, which was 41-70 years.

In the present study the incidence in the age group of 4160 years was $65.13 \%$, while that of Srinivasan was $79.55 \%$. However, at MSKCC, New York, a peak incidence was noticed in the 51-80 years' age group (75.19\%). The incidence below 40 years was $22.37 \%$ in the present study, while it was over $11.36 \%$ in the study by Srinivasan and $6.22 \%$ at MSKCC, New York. There were no patients older than 70 years in the present study, whereas the incidence was $2.27 \%$ in the study by Srinivasan and $27.89 \%$ at MSKCC. The reason could be due to the decreased mean age of survival of Indians compared to that of the population in the developed nations of the west.

\section{Sex Incidence}

Table 1 shows the sex incidence of malignant tumours. It was noted that $64.47 \%$ of malignancies occurred in men compared to $35.53 \%$ in females. This is very much similar to that seen in study by Borch K. et al ${ }^{9}$ in Sweden with a high male sex incidence, where $61.07 \%$ cases were males and $38.43 \%$ were females. Thus, both studies show a male-to-female ratio of 2:1 in gastric cancer incidence.

\section{Distribution of Malignant Tumours according to the Anatomical Site}

Table 3 illustrates the location of gastric adenocarcinoma and also presents the relevant comparative date. The current study and Borch K. et al study show a high incidence of malignancies in the body and antrum. In the data from Tata Memorial Hospital Cancer Registry as shown in Table 10 for the period from 1987 to 1993 , it has been found that there is an increased incidence (43.78\%) of malignancies in the distal third of the stomach.

\section{Signs and Symptoms}

Table 7 shows the incidence of signs and symptoms in the current study. Most patients presented with abdominal pain and vomiting. This correlates well with the incidence of signs and symptoms in advanced gastric cancer reported by Sleisenger et $\mathrm{al}^{10}$ as shown in Table 11 , in which the most common symptoms were abdominal pain and loss of weight. Other common symptoms were nausea, vomiting and loss of appetite.

\section{Clinical Staging of Gastric Adenocarcinoma}

Staging was done based on TNM classification as shown in Table 5 on all gastrectomy specimens received in our institution. Table 6 shows the comparison in clinical staging between the current study and Borch K. et al ${ }^{9}$ study. In the current study excluding the undefined category, most cases were in stage II (16.90\%), whereas in Borch K. et al study most of the cases were in stage IV (28\%); in another study by Jin Pok Kim of the Department of Surgery in Seoul National University Hospital from 1981 to 1996, most of the patients were in stage IIIB (22.3\%).

In our institution, palliative bypass surgery is done for advanced stages of gastric cancer, which may explain the apparent low incidence of stage IV disease in the gastrectomy specimens.

\section{Histologic Distribution of Malignant Tumours of the Stomach}

The incidence of the various histologic types of the malignant tumour of the stomach is given in Table 7 and compared with the study by Srinivasan. In both the studies, the most common histological type is adenocarcinoma. In the study by Borch $\mathrm{K}$. et $\mathrm{al}^{9}$ as shown in Table 6 also, the commonest histological type was adenocarcinoma making up $96.32 \%$ of total malignancies.

In the present study the incidence of mucinous adenocarcinoma was only $8.55 \%$, while it was $29.55 \%$ in the study by Srinivasan. The incidence of neuroendocrine tumours was $3.29 \%$ in the present study, while in the study by Borch $\mathrm{K}$. et al it was $0.53 \%$. The incidence of lymphomas was low in all three studies.

\section{Tumour-Like Lesions of the Stomach}

The incidence of tumour-like lesions of the stomach in comparison with the study by Seifert Elster is shown in Table 8. Hyperplastic polyps were the commonest in both the studies with an incidence of $66.67 \%$ in the current study and $57.64 \%$ in the study by Seifert and Elster. Hamartomatous polyps showed an incidence of $33.33 \%$ in the current study, whereas it was not encountered in the other study.

\section{Benign Neoplasms of the Stomach}

Benign epithelial tumour (Adenoma) was not encountered in the current study.

\section{Malignant Tumours of the Stomach}

The major histologic type of cancer arising in the stomach is adenocarcinoma with incidence in the sixth and seventh decades and a male-to-female ratio of 2:1.

The current study showed peak incidence in the 41-60 years' age group as shown in Table 13 and a male-to-female ratio of 2:1 approximately as shown in Table 14 . The study by Srinivasan also showed an increased incidence in 41-60 years' age group (79.5\%).

In the current study, the commonest site of adenocarcinoma was the antrum. This correlates well with the data obtained from the Tata Memorial Hospital Cancer 
Registry, which also show a high incidence of distal third cancers. Grossly, most of the tumours were ulcero-infiltrative in nature (Fig. 2). The diffusely infiltrative carcinomas showed diffusely thickened gastric wall with three cases of linitis plastica type of tumours.

Microscopically, adenocarcinoma has been classified into papillary, tubular, mucinous and signet ring cell carcinoma as per the W.H.O. classification. This classification is based on the dominant pattern, since most adenocarcinomas show different histological features depending upon the layer in which the tumour infiltrates.

The other histological classifications of gastric adenocarcinomas are given in Table 15.

\section{Papillary Adenocarcinoma}

Papillary adenocarcinomas showed prominent intraglandular folding and projections with cuboidal to high columnar carcinoma cells lining the narrow bands of interstitial tissue. Although some tubular formation was seen, the papillary pattern was evident in cystic areas. The present study included three cases of papillary adenocarcinoma with one of them showing lymph node metastases.

\section{Tubular Adenocarcinoma}

This tumour showed tumour cells arranged in branching tubular pattern. According to the degree of tubular formation, it was graded into well, moderately and poorly differentiated.

\section{Well Differentiated}

This tumour showed a distinct glandular pattern with columnar epithelium throughout and amount of stroma was moderate or small. Invasion of muscle coat by the tumour cells are also seen.

\section{Moderately Differentiated}

This tumour showed small or incomplete tubular structures with cuboidal or flat epithelium. A cribriform structure was occasionally found.

\section{Poorly Differentiated}

This tumour showed a few glandular structures, which were recognized only with difficulty (Fig. 1). In the current study, there were 66 cases of well-differentiated adenocarcinoma, 7 cases of moderately-differentiated adenocarcinomas and 46 cases of poorly-differentiated adenocarcinomas. Three of the total gastrectomy specimens of poorly-differentiated adenocarcinoma showed diffuse thickening of the gastric wall producing linitis plastica (Fig. 2).

The mucin secreted by adenocarcinomatous cells is mainly intestinal acidic mucins, which was strongly positive for Alcian Blue at PH 2.5 (Fig. 3) and also PAS positive (Fig. 4).

\section{Early Gastric Carcinoma}

In the current study there were 4 cases of early gastric carcinoma limited to the mucosa and submucosa, as described by the Japanese Gastroenterological Endoscopy Society. In the Japanese National Statistics Type IIC was the most common (33.8\%) followed by Type IIC + Type III (23.4\%).

In the current study, there were 3 cases of gastric adenocarcinoma arising from the gastric remnant. In one patient poorly-differentiated adenocarcinoma developed in the gastric remnant, 20 years after gastrectomy done for benign peptic ulcer.
Two cases of Krukenberg tumour of ovary were encountered in the present study (Fig. 5). One patient was a 19-year-old female with poorly-differentiated adenocarcinoma with secondary involvement of the left ovary. In the other patient (34-year-old Female) both the ovaries showed diffuse infiltration by tumour cells with many signet ring shaped tumour cells (Fig. 6). The tumour cells were PAS positive (Fig. 7) and Alcian blue positive.

In the current study the associated intestinal metaplasia was noted in seven cases of adenocarcinoma, of which three cases showed complete metaplasia. Complete intestinal metaplasia showed positivity with Alcian blue PAS stain with the goblet cells containing acidic and neutral mucins staining purple (Fig. 8). Chronic atrophic gastritis was seen in three cases and dysplasia in one case.

\section{Mucinous Adenocarcinoma}

In the current study there were 13 cases of mucinous adenocarcinoma (8.55\%), whereas in the study by Srinivasan the incidence was $29.54 \%$ in some of the cases, grossly itself the mucin was clearly visible (Fig. 9). Microscopically, distended glands showing fragmentation were seen floating in mucin lakes (Fig. 10). In a few cases, signet ring cells were also seen.

\section{Signet Ring Cell Carcinoma}

It is an adenocarcinoma in which the tumour cells contain various amounts of mucin compressing the nuclei giving it a signet ring shape.

In the current study, there were 7 cases of signet ring cell carcinoma (4.61\%). Microscopically, the tumours showed diffuse infiltration by signet ring cells with surrounding zones of desmoplasia.

\section{Adenosquamous and Squamous Cell Carcinoma \\ Incidence of adenosquamous and squamous cell carcinomas are very rare. (Mori et al) No adenosquamous or squamous cell carcinoma was encountered in the present study.}

\section{Undifferentiated Carcinoma}

It is defined by W.H.O. as a tumour, which lacks specific evidence of differentiation, either structurally or functionally. No such tumour was encountered in the current study.

\section{NEURO-ENDOCRINE TUMOURS OF THE STOMACH Carcinoids}

The tumour cells showed uniform centrally located nuclei with finely stippled chromatin, small nucleoli and infrequent mitosis (Fig. 11). Positive immunoreactivity for chromogranin could be demonstrated in the section (Fig. 12).

\section{Gastro-Intestinal Stromal Tumours}

In the current study, no such tumour was encountered.

\section{Malignant Haematopoietic and Lymphoid Neoplasms}

In the current study, there were 5 cases of primary gastric lymphomas of which 2 cases showed characteristic features of low-grade MALT lymphomas (MALTomas).

Of the other 3 cases in the present study, two were of the diffuse small cell type and the other case showed infiltration by a mixture of small and large cells with serosal invasion.

Gomori's staining method for reticulin fibers was used to differentiate lymphoma from poorly differentiated carcinoma. 
In the current study the incidence of lymphoma was $3.29 \%$, whereas in the study by Srinivasan it was $2.27 \%$ and Boech K. et al study it was $1.58 \%$.

\section{TUMOUR-LIKE LESIONS \\ Hyperplastic Polyp}

Two cases of hyperplastic polyps are reported in the current study. A 45-year-old female presented with complaints of abdominal pain from 1 month and melena. OGD showed a highly vascular sessile polyp in the fundus just distal to oesophagogastric junction. Wedge resection was done. Microscopically, there was no evidence of any dysplastic change.

\section{Hamartomatous Polyp}

In the current study, there was one case of hamartomatous polyp in a 74-year-old male in the antrum. Microscopically, the polyp showed gastric glands without any dysplastic change with inflammatory cell collection in the lamina propria. The polyp showed a central core of smooth muscle bundle.

\section{SUMMARY AND CONCLUSION}

1. In the current study, the incidence of tumours and tumourlike lesions of the stomach was $0.47 \%$.

2. The current study did not encounter any benign tumours of the stomach.

3. Malignant tumours of the stomach comprised $98.1 \%$ of all tumours and tumour-like lesions of the stomach with a male-female ratio of 2:1.

4. Among the tumour-like lesions, hyperplastic polyps were the commonest with an incidence of $66.67 \%$.

5. The peak age incidence for majority of gastric malignancies $(65.13 \%)$ was seen in the age group between 41 and 60 years and correlates well with the other Indian study.

6. The commonest clinical symptoms were abdominal pain and vomiting.

7. In the current study, four cases of early gastric carcinoma limited to the mucosa and submucosa were identified.

8. Adenocarcinoma was the predominant histological type of malignancy (93.42\%) and well-differentiated adenocarcinoma was the commonest.

9. Regional lymph node involvement was seen in 65 cases, of which 31 cases were positive histologically.

10. Reticulin stain was of considerable use in delineating lymphomas from poorly-differentiated carcinoma.
11. PAS and Alcian blue stain were useful to differentiate adenocarcinoma, mucinous adenocarcinoma and signet ring cell carcinoma.

12. The current study did not include any gastrointestinal stromal tumour.

13. Immunohistochemistry for chromogranins to confirm the diagnosis of carcinoid tumour and leukocyte common antigen and cytokeratin for MALTomas were done.

14. Associated intestinal metaplasia was noted in 7 cases of adenocarcinoma, of which 3 cases showed complete intestinal metaplasia.

\section{REFERENCES}

1. Parkin DM, Pisani P, Ferlay J. Estimates of the world wide incidence of eighteen major cancers in 1985. Int Journal of Cancer 1993;54(4):594-606.

2. Mohandas KM, Aabha N. Epidemiology of digestive tract cancers in India. II. Stomach and gastrointestinal lymphomas. Indian Journal of Gastro Enterology 1998;17:24-27.

3. Stevens A, Wilson I. The haematoxylins and eosin. In: Bancroft J, Stevens A, eds. Theory and practice of histological techniques. $4^{\text {th }}$ edn. Edinburg: Churchill Livingstone 1996:136.

4. Oota K, Sobin LH. Histological typing of gastric and esophageal tumours. International histological classification of tumours no 18. Geneva: WH01977:37-46.

5. Alexander RH, Kelsen DG, Tepper JC. Cancer of the stomach. In: DeVita VT, Hellman S, Rosenberg SA, eds. Cancer: principles and practice of oncology. $5^{\text {th }}$ edn. Philadelphia: Lippincoot-Raven 1997:1030.

6. Carneiro F, David L, Seruce R. Hyperplastic polyposis and diffuse carcinoma of the stomach. A study of family. Cancer 1933;72(2):323-329.

7. Srinivasan R. Malignant neoplasm of the gastrointestinal tract. Acta Cytology 1993;37:894-898.

8. Brennan MF, Karpeh MS. Surgery for gastric cancer: the American view. Semin Oncol 1996;23(3):352-359.

9. Borch $\mathrm{K}$, Jonsson B, Tarpila E, et al. Changing pattern of histological type, location, stage and outcome of surgical treatment of gastric carcinoma. British Journal of Surgery 2000;87(5):618-626.

10. Goodwin CS, Armstrong JA, Chilvers T, et al. Transfer of campylobacter pylori and campylobacter mustelae to helicobacter gen. nov. as helicobacter pylori comb. nov, and helicobacter mustelae comp, nov. respectively. In J Syst Bacteria 1989:39(4):397-405. 